\title{
Heartland Sul-americano? Dos discursos geopolíticos à territorialização de um novo triângulo estratégico boliviano
}

\author{
Matheus Hoffmann Pfrimer*
}

Resumo: Do ponto de vista da geopolítica crítica as teorias da geopolítica sul-americana se destacam, já que exerceram grande influência na vida política dessa região. Dotada de uma diversidade de recursos naturais e variada fisiografia, a Bolívia chamou a atenção pelas perdas territoriais e de seu acesso ao mar. No pensamento geopolítico coexistem pelo menos três visões sobre a Bolívia. A primeira é a de que a Bolívia era um absurdo geográfico. A segunda visão apresentava a Bolívia como área estratégica de contenção entre Argentina e Brasil, a partir do conceito de triângulo estratégico boliviano. A terceira vertente vem afirmando que a Bolívia é uma área estratégica para a integração sul-americana. O presente estudo visa verificar as transformações da morfologia, função e estrutura territoriais na Bolívia de forma a distinguir quais desses postulados atualmente se aplicam no território boliviano.

Palavras-chave: Bolívia, Heartland Sul-americano, triângulo estratégico boliviano, Pensamento Geopolítico.

\begin{abstract}
From the standpoint of critical geopolitics, the theories of South American geopolitics stand out, once they influenced the political life in this region. Endowed with a great variety of natural resources and a diverse physiography, Bolivia drew the geopoliticians attention for losing a great part of its original territory and its shore. There are at least three different points of view about Bolivia within South American geopolitical thought. The first one characterized Bolivia as a geographical nonsense. The second view presented Bolivia as an important area of containment carried on by Brazil and Argentina. The third, and last one, has argued that Bolivia is a strategic area for South American integration purposes. This study aims to determine the changes in morphology, function and territorial structure in Bolivia in order to distinguish which of these discourses are territorialized today in Bolivia.
\end{abstract}

Key words: Bolivia, South American Heartland, Bolivian strategic triangle, Geopolitical thought.

\section{Introdução}

Vários geógrafos vêm ressaltando a importância de se retomar uma análise crítica do pensamento geopolítico sul-americano. Geógrafos como Becker (1980, 1988), Costa (2008), Martin (1992) vêm empreendendo uma revisão crítica dos conceitos e teorias do Pensamento Geopolítico Sul-americano há mais de vinte anos, uma vez que a política do subcontinente foi diretamente influenciada pelas doutrinas geopolíticas regionais.

Esse intento não se restringiu a geógrafos do subcontinente. Há algum tempo, também autores anglo-saxões como Hepple (1986a,
2004), Dodds (2000), Kelly (1997) e Child (1988), partindo de uma perspectiva crítica, advertiram sobre a importância de se revisar os postulados do pensamento geopolítico sul-americano. Razões para isso existem: a) a geopolítica crítica tem se centrado em sua maior parte apenas na análise do pensamento geopolítico anglosaxão; b) a geopolítica teve grande influência sobre a vida política sul-americana, uma vez que sua reputação no continente é positiva; c) "muitas facetas da política externa sul-americana parecem corresponder (...) ao formato das teorias 
geopolíticas"; d) uma boa parte dos renomados geopolitólogos sul-americanos foi ou ainda são influentes na política de seus países (KELLY, 1997, p. 13-14).

Atualmente a geopolítica pós-moderna vem empreendendo uma reflexão mais acurada da geopolítica clássica, principalmente no que concerne aos conceitos e discursos geopolíticos. Agnew e Corbridge (1995) afirmam que uma ordem geopolítica vem sempre pautada por discursos geopolíticos, que oferecem legitimidade à materialidade de um arranjo territorial. Outros autores como Dodds (2007) e Ó'Tuathail (1996) afirmam que deve-se estudar as teorias geopolíticas como construtos teóricos para legitimar práticas espaciais hegemônicas, e, portanto, os discursos são essenciais para compreendê-las. Porém, de outra forma, diríamos que os discursos procuram legitimar diversas práticas geopolíticas, representadas pelas decisões e ações tomadas por diferentes atores em diversas escalas, no entanto, a recíproca também é verdadeira, pois as práticas também influenciam os discursos. A partir da constituição dessas práticas vão se estabelecendo diversos arranjos territoriais ${ }^{1}$. Dessa forma, o que ocorre é uma interação entre discursos, práticas e arranjos territoriais, não havendo uma preponderância dos discursos sobre as demais categorias, como querem afirmar os autores da geopolítica pós-moderna (KELLY, 2006; TAYLOR, FLINT, 2000, DODDS, 2000). Assim, uma vez que boa parte desses discursos geopolíticos parece corresponder aos arranjos territoriais na Bolívia, não faz mais sentido apenas examinar de que forma a geopolítica legitimou essas práticas sociais (PFRIMER, ROSEIRA; 2009).

É notório que vários conceitos da geopolítica clássica europeia foram arregimentados pelo pensamento militar sul-americano, uma vez que nas escolas militares do continente conformavam verdadeiros núcleos de doutrinamento dos postulados geopolíticos europeus e americanos. Um dos conceitos mais difundidos nesses centros se fundamentou na transposição do conceito de heartland, cunhado pelo geógrafo Halford Mackinder (1904), para a situação geográfica boliviana pelos diferentes autores sul-americanos (VEGA, 1968, 1982; BAPTISTA GUMUCIO, SAAVEDRA WEISE, 1978). Por se situar geograficamente no centro do continente, a Bolívia era vislumbrada como uma região estratégica na região. Naturalmente boa parte desses discursos buscava justificar uma geopolítica prática e seus projetos ambiciosos em território boliviano. Isso pode ser comprovado não apenas pelos discursos geopolíticos como também pelas ações expansionistas de diversos atores sobre Bolívia. Por esses fatores, o caso boliviano se estabelece como uma boa oportunidade de se avaliar os discursos e práticas geopolíticos sulamericanos e os graus de territorialização das diretrizes neles intencionadas.

Para tanto, pretendemos retomar os discursos geopolíticos sobre a Bolívia, por meio do conceito de triângulo estratégico boliviano e outras teorias, e contrapô-los ao arranjo territorial boliviano, de forma a elucidar a sua verdadeira concretude. Seriam os discursos geopolíticos sobre a Bolívia apenas estratégias discursivas do poder, ou as diretrizes conceituais desses discursos realmente se materializaram em território boliviano, por meio de práticas geopolíticas, deixando assim de ser apenas construtos meramente teóricos para se plasmarem no real concreto? Levando esse questionamento adiante, em um primeiro momento classificamos os diferentes discursos geopolíticos sobre a Bolívia de acordo com o contexto histórico. Desta forma, dividimos o horizonte temporal desse estudo em período de contenção (até o final da década de 70) e período de integração (a partir de 1980 até o período atual). Por meio dessa classificação partimos então para uma apreciação das práticas geopolíticas e seus consequentes arranjos territoriais na Bolívia, verificando a sua densidade técnica, sua morfologia e seu processo de transformação em um novo contexto. Em uma terceira fase confrontamos os discursos geopolíticos aos arranjos territoriais bolivianos, apreciando criticamente quais discursos geopolíticos acabaram se plasmando em maior ou menor intensidade no território boliviano.

\section{Bolívia: um hiato em meio a discursos geopolíticos}

Buscamos nesse tópico avaliar de que forma se estruturou a visão da geopolítica formal ${ }^{2}$ a respeito da Bolívia, isto é, de que forma as teorias e os discursos geopolíticos foram pouco a pouco 
estruturando uma visão geral sobre a Bolívia no contexto sul-americano, interagindo com as práticas geopolíticas.

Nos manuais geopolíticos pode-se encontrar pelo menos três posições em relação à Bolívia (ver Quadro 1). A primeira aponta a Bolívia como um absurdo geográfico, um país tampão comprimido entre as pretensões de Argentina, Brasil e Chile. Para esses geopolitólogos, a presença de características fisiográficas tão díspares, como a sua orografia variada, impediu a integração das diferentes regiões do território boliviano, inviabilizando a sua própria existência enquanto país. Autores clássicos como Derwent Whittlesey e Badia Malagrida esquadrinharam a situação boliviana como a de um "pseudo" Estado. Para o geógrafo americano a Bolívia era um estado "deficiente" (handicaped state) devido à dificuldade de integração nacional provocada pela orografia diversa de seu território e sua deficiente política territorial (WHITTLESEY, 1944, p. 545). O geógrafo espanhol afirmou categoricamente que a Bolívia era um "absurdo geográfico" (BADIA MALAGRIDA, 1919 apud QUIROGA, 1978, p. 88) uma vez que seu território não coincidia com nenhuma das regiões físicas sul-americanas. Segundo o autor espanhol, isso era sinal de que não havia uma articulação coerente entre o solo e a sociedade boliviana. Esse tipo de posição foi defendida em sua maior parte por autores oriundos de escolas geopolíticas externas ao contexto sul-americano. Mesmo após a passagem do período de contenção para o de integração, essa posição geopolítica exógena tem procurado afirmar a insignificância boliviana em relação ao contexto sul-americano, devido a seu enclausuramento geopolítico e ausência de unidade política (GLASSNER, 1988; LAVAUD, 2000; HEPPLE, 2004).

\begin{tabular}{|c|c|c|}
\hline $\begin{array}{c}\text { Visão dos discursos } \\
\text { geopolíticos a respeito da } \\
\text { Bolívia }\end{array}$ & $\begin{array}{l}\text { Período de contenção } \\
\text { (até final da década de } 70 \text { ) }\end{array}$ & $\begin{array}{l}\text { Período de integração } \\
\text { (início da década de } 80 \text { em } \\
\text { diante) }\end{array}$ \\
\hline $\begin{array}{c}\text { Bolívia como absurdo } \\
\text { geopolítico ou com } \\
\text { nenhuma importância } \\
\text { geopolítica }\end{array}$ & $\begin{array}{l}\text { Badia Malagrida (1919), } \\
\text { Bowman (1928), } \\
\text { Whitlesey (1944). }\end{array}$ & $\begin{array}{l}\text { Glassner (1988), } \\
\text { Hepple (2004), } \\
\text { Lavaud (2000). }\end{array}$ \\
\hline $\begin{array}{c}\text { Bolívia como área } \\
\text { estratégica para a } \\
\text { contenção sul-americana }\end{array}$ & $\begin{array}{l}\text { Cañas Montalva (1959), } \\
\text { Carlés (1950), } \\
\text { Couto e Silva (1955), } \\
\text { Guglialmelli (1975), } \\
\text { Pinochet (1977), Rodrigues } \\
\text { (1947), } \\
\text { Tambs (1965), } \\
\text { Travassos (1935), } \\
\text { Videla (1980) }\end{array}$ & Meneses Ciuffardi (1981), \\
\hline $\begin{array}{c}\text { Bolívia como área } \\
\text { estratégica para integração } \\
\text { sul-americana }\end{array}$ & $\begin{array}{l}\text { Mendoza (1935), } \\
\text { Valencia Vega (1968), } \\
\text { Zavaleta Mercado (1967) }\end{array}$ & $\begin{array}{l}\text { Costa (1999), Egler (2006), } \\
\text { Marini (1980), Martin (2007), } \\
\text { Quagliotti de Bellis (1990), } \\
\text { Valencia Vega (1982), } \\
\text { Velilla de Arréllaga (1982) }\end{array}$ \\
\hline
\end{tabular}

Quadro 1. Principais Teorias Geopolíticas a respeito da Bolívia no período de contenção e integração sul-americana. Fonte - Organizado por Pfrimer (2010).

Um segundo grupo de autores geopolíticos procurou ver a questão por uma ótica diferente. Em um período em que argentinos e brasileiros se confrontavam pela preponderância continental, o território boliviano se tornava o "eixo de vertebração" do poder na América do Sul. Outro aspecto marcante nessa posição era a fobia da ascensão do comunismo na região, ainda mais após a guerrilha do "Che" em pleno Chaco boliviano (DODDS, 2000, p. 169). Dessa forma, boa parte dos discursos brasileiros e argentinos durante a contenção caracterizava a Bolívia como 
uma região estratégica a ser controlada ainda que indiretamente ${ }^{3}$. Uma das teorias geopolíticas mais significativas que expressa esse discurso é a do triângulo estratégico boliviano formulada pelo general brasileiro Mário Travassos ainda nos anos 30.

Para Travassos os principais contrastes fisiográficos do subcontinente giravam em torno dos antagonismos Atlântico-Pacífico e Bacia Platina e Bacia Amazônica. Para o militar brasileiro, dentre os dois antagonismos o último era o mais acentuado e colocava em jogo interesses das duas potências regionais: Brasil e Argentina. No seu pensamento geopolítico, ambos os antagonismos se materializavam em pleno território boliviano conformando um triângulo onde se confrontavam interesses brasileiros (influências amazônicas), argentinos (influências platinas) e bolivianos (influências andinas). Segundo Travassos, "a chave desse problema se encontrava no chamado triângulo econômico Cochabamba-Santa Cruz de La Sierra-Sucre, verdadeiro signo da riqueza boliviana" (TRAVASSOS, 1935, p. 41). Ou seja, nessa nova corrente a Bolívia deixava de ser insignificante para ganhar atenção dos projetos expansionistas das semipotências sul-americanas.

Boa parte do pensamento geopolítico sulamericano consubstanciou a sua análise sobre a geopolítica da região e da Bolívia a partir da teoria de Travassos. No pensamento geopolítico brasileiro outros autores também colocaram a Bolívia como área de confrontação entre interesses brasileiros e argentinos (KELLY, 1988, p. 114; HEPPLE, 1986b). Lysias Rodrigues ressaltou o conceito-chave de Travassos a partir da ideia de Puncti Dolentes. Rodrigues buscou a partir desse conceito representar pontos de tensão geopolítica no sub-continente, sendo o principal deles o que se cristalizava na região do triângulo estratégico boliviano (RODRIGUES, 1947 , p. 65). Golbery do Couto e Silva também deu maior contextualização ao conceito de Travassos a partir da idéia de "Área de Soldadura continental" (COUTO E SILVA, 1955, p. 127-128).

No pensamento geopolítico argentino, a obra de Travassos foi também fortemente acolhida principalmente pela Escuela Superior de Guerra (DODDS, 2000, p. 160). Diferentes geopolitólogos argentinos vislumbraram "o território boliviano como um espaço vazio a ser preenchido" (PITMANN 1981 apud DODDS, 2000, p. 161) e também como uma questão chave da política externa argentina (RUSSEL, 1988, p. 72; DODDS, 2000; CARLÉS, 1950; GUGLIALMELLI，1975; ROMANO apud PEREIRA, 1974, p. 72; MACHICOTE apud MELO, 1997, p. 152). Do lado chileno o espectro da posição brasileira e argentina também se fez refletir nos meios militares. Autores como Cañas Montalva (1959) e o general Augusto Ugarte Pinochet (1977) ressaltavam que a Bolívia era uma área estratégica para a preservação dos interesses chilenos em relação à Argentina e ao Peru (PITMANN, 1988). O exemplo mais prático da visão chilena sobre a Bolívia pode ser contemplado ao se analisar o Plano Alpaca que visava a expansão chilena sobre terras bolivianas.

Após a passagem para um período caracterizado pela preponderância da integração sob a contenção, essa visão defendida principalmente por autores argentinos, brasileiros e chilenos foi sendo relegada a último plano. Em contraposição a ela, ainda no período de contenção, autores bolivianos exaltaram os fatores geográficos do país como símbolos de identificação da nação boliviana (MENDOZA, 1935; ZAVALETA MERCADO, 1967) dando origem a uma terceira visão que caracteriza a Bolívia como uma área estratégica e rica em recursos uma vez que nela se encontra o Divortium aquarium (divisor de águas) sul-americano. Posteriormente, outros autores bolivianos acrescentaram a essa posição a ideia de que a integração nacional da Bolívia era fundamental para o equilíbrio territorial sulamericano e dotado desse epíteto, tornava-se evidente que o território boliviano era um ponto fulcral para a integração das diversas regiões do continente sul-americano (VALENCIA VEGA, 1968; PAREJA, 1978). Somente assim o "cercamento" argentino-brasileiro sobre o território nacional seria atenuado. Embora essa tese expressasse um nacionalismo boliviano, posteriormente autores paraguaios e uruguaios passaram a defender a tese de que a Bolívia, assim como o Paraguai e Uruguai, deviam se aliar para fazer face aos avanços das duas semipotencias (VELILLA DE ARRÉLLAGA, 1982; QUAGLIOTI DE BELLIS, 1988; QUAGLIOTI DE BELLIS, 1990), daí a gênese da organização 
URUPABOL formada em 1981. Anteriormente, outros intentos de cooperação regional já haviam sidos organizados como a Comunidade Andina de Nações (CAN), Associação Latino-Americana de Livre Comércio (ALALC), porém sem avanços substanciais diante de uma contenção acentuada.

O ponto de passagem da preponderância da contenção para a preponderância da integração se deu a partir da formulação do Fundo Financeiro para o Desenvolvimento da Bacia do Prata (FONPLATA). Logo em seguida, outras iniciativas de integração ganharam maior espaço como a Associação Latino Americana de Integração (ALADI) e mais tarde o Mercado Comum do Sul (MERCOSUL). Evidentemente, a partir desses eventos, os discursos dos países $A B C$ tomaram um rumo oposto àquele apresentado durante a contenção. No pensamento geopolítico argentino, Marini (1980) passou a defender a necessidade da integração argentino-brasileira face à presença americana na região, e nesse contexto a Bolívia se tornaria uma área importante para a integração regional. O mesmo aconteceu com o pensamento geopolítico brasileiro (KELLY, 1988, p. 121; EGLER, 2006). Costa (1999) apresenta a Bolívia como uma das regiões fundamentais para a articulação territorial no subcontinente. Martin (2007) trata o território boliviano como crucial para integração férroviária e a consolidação da integração territorial sul-americana sob a ótica de uma geoeconomia meridionalista.

De forma geral, nota-se que os discursos geopolíticos exógenos ao contexto sul-americano procuram caracterizar a Bolívia como uma área inexpressiva, principalmente na escala global. Porém, deve-se ressaltar que o território boliviano continua sendo uma área estratégica na escala sulamericana, principalmente para as finalidades do projetos de integração regional. Evidentemente, boa parte desses discursos exógenos também procuraram legitimar posições de poder. Assim sendo, esses discursos estariam procurando subestimar a posição estratégica da Bolívia, com o objetivo de dissuadir ideologicamente os projetos de integração territorial sul-americana, que, afinal, se apresentam como alternativas mais palpáveis do que outros projetos de integração regional como a Área de Livre Comércio das Américas
(ALCA).

De outro lado, percebe-se que os discursos geopolíticos dos países $\mathrm{ABC}^{4}$ caracterizavam a Bolívia como uma área de substancial importância para a defesa de seus interesses nacionais e a prepoderância em todo subcontinente. Entretanto, o arrefecimento das políticas de contenção e construção de um novo cenário pautado majoritariamente na integração fizeram com que o território boliviano fosse apreciado de forma diferente pela nova agenda regional. Foi atribuído ao país andino uma nova função: a de núcleo de integração sul-americana. Naturalmente esses discursos também expressam intencionaldades a partir das quais transparecem não apenas objetivos benignos aos interesses dos países menos desenvolvidos da região. Os projetos de integração regional produzem asimetrias ecônomicas e ambientais, principalmente nos teritórios dos países menos desenvolvidos, por isso mesmo o conceito de integração, em alguns casos, pode significar tudo, menos coligar territórios nacionais para fins mútuos.

Marcando uma terceira visão sobre o seu próprio território, os discursos bolivianos procuraram valorizá-lo, observando a sua reconhecida importância estratégica, porém, não para a finalidade de contenção, mas sim para a de integração nacional e regional de forma a fazer face a interesses externos aos sul-americanos. Verifica-se ideologicamente que o imaginário geopolítico boliviano procura amalgamar o fragmentado território boliviano, com finalidade de solidificar a indentidade nacional a partir de suas características fisiográficas. Daí por exemplo a tese do "macizo boliviano" de Jaime Mendonza (1935), que defendia a ideia de que ao invés de fragmentar as regiões bolivianas, a fisiografia do território nacional era um fator de coesão nacional por meio da identificação com a paisagem andina. Dessa forma, fica evidente que os discursos geopolíticos a respeito do território boliviano procuraram legitimar práticas geopolíticas, resta saber qual delas prevaleceu no arranjo territorial boliviano.

\section{A Régua e compasso: a arquitetura dos discursos geopolíticos em território boliviano} Do ponto de vista das práticas geopolíticas e 
da morfologia territorial existe um descompasso entre os períodos aqui analisados. Se no início da contenção os discursos geopolíticos eram apenas narrativas especializadas do poder, no final do período de contenção, fica explícito que esses discursos acabaram se materializando no território boliviano embora o arranjo anterior tenha também interferido nesse processo de reestruturação territorial. Naturalmente, a fixação de uma rede de objetos técnicos e a consequente densificação da rede urbana foram fruto da ingerência brasileira e argentina nas políticas territoriais bolivianas por meio de golpes de Estado e incentivos econômicos (SCHILLING, 1981; MELLO, 1997; ZANATTA, 2006; PFRIMER, ROSEIRA, 2009 ). Assim sendo, buscamos nesse tópico apresentar de que forma os discursos geopolíticos sobre a Bolívia se aliaram às práticas geopolíticas e influenciaram as políticas territoriais no país andino, vindo a territorializar várias das ideias presentes nesses postulados geopolíticos.

Nos discursos geopolíticos sul-americanos muitos se fala da Bolívia como área de integração entre Bacia do Prata e Amazônica, porém a questão também girava em torno da integração nacional de um país regionalmente dividido por áreas desconexas entre si. Até 1950, grande parte do ecúmeno boliviano se encontrava presente apenas no altiplano. O eixo de ocupação tinha um claro delineamento norte-sul sobre o altiplano. Estendendo-se desde a fronteira argentina por meio de Tarija, passando pelos principais centros mineradores como Potosi, Sucre e Oruro e indo até La Paz. Mais da metade do território nacional situado nos llanos encontrava-se parcamente povoada. Essa terras orientais que ocupam aproximadamente $60 \%$ do território boliviano foram durante muito tempo consideradas pelo imaginário popular como tierras baldias, ou seja, inúteis uma vez que não tinham tanto minério como nas terras do altiplano.

Ainda nos anos 40, o Estado boliviano passou a se preocupar com a ocupação e valorização do território oriental. Visando resolver o desequilíbrio territorial nacional e o monopólio da mineração sobre a economia, um novo planejamento territorial, orientado pelo economista americano Marvin Bohan, passou a ser implementado. Tratava-se de utilizar para financiamentos do setor agroexportador em Santa Cruz todo o capital arrecadado pela tributação da atividade mineradora no altiplano. Nesse contexto, Santa Cruz deixaria de ser uma cidade média para se tornar uma área propícia à economia moderna e voltada para mercado internacional. Após a revolução de 1952, e a entrada no poder do governo popular do MNR, 0 plano ganharia ainda mais apoio, com a construção de infraestrutura de transportes e serviços.

O objetivo principal almejado pelo novo planejamento territorial e a geopolítica prática boliviana era a criação de um eixo de ocupação em sentido leste-oeste. Esse projeto se baseava na teoria dos corredores econômicos, do qual La Paz, Cochabamba e Santa Cruz de La Sierra seriam polos de desenvolvimento econômico. Ademais, estando cada polo de desenvolvimento localizado em um piso ecológico (altiplano, vales e llanos respectivamente) facilitaria a integração nacional.

Essas medidas promovidas pelas políticas territoriais bolivianas não tardaram a modificar o arranjo territorial. A abertura de uma série de estradas promoveu grande fluxo migratório e a criação de uma série de novos municípios. A população nacional presente nos llanos passaria de $12 \%$, em 1954 a aproximadamente 30\%, em 2001 (INE, 2002). Além disso, Santa Cruz veio a ser no final dos anos 1990 o principal centro econômico nacional com mais 30 \% do PIB (INE, 2001).

Naturalmente, a inversão de financiamentos em Santa Cruz não foi mera obra do acaso. Além do desenvolvimento nacional, o fator geopolítico e a influência estrangeira foram preponderantes para que Santa Cruz se tornasse polo de atração. Após a ascensão de Hugo Banzer, em 1971 na Bolívia, sob os auspícios do regime militar brasileiro e do governo americano, mais de $70 \%$ dos créditos concedidos pelo Banco Agrícola e a Corporação de Desenvolvimento Regional foram destinados à Santa Cruz (DUNKERLEY, 1984, p. 221). O governo americano, ao conceder empréstimos à Bolívia, condicionou a realização dos empréstimos ao requisito de que mais da metade deles fossem implementados em Santa Cruz de La Sierra (ANDRADE, 2007, p. 132). Nesse período, os americanos já tinham se decidido pelo Brasil como aliado regional, e, portanto, fazia parte do interesse americano que o Brasil mantivesse sua influência em território boliviano por meio da 
atração de Santa Cruz à esfera política brasileira. Nesse sentido outras escalas maiores, além da regional e nacional, acabaram interferindo nas políticas territoriais bolivianas. Não é por acaso que boa parte dos problemas da integração nacional boliviana advém da sua própria política externa pendular entre Brasil e Argentina, assegurando assim certo equilíbrio geopolítico entre Brasil e Argentina (KELLY, 1997). Trata-se de uma forma de sobreviver incrustada entre as influências das duas potências regionais. Naturalmente, o preço de tal empreitada é pago pela falta de integração e risco de balcanização.

A disputa pela hegemonia regional em território boliviano fez com que Brasil e Argentina aplicassem boa parte dos postulados de sua geopolítica formal. Em relação à geopolítica prática brasileira, não apenas a ligação viária bioceânica seria o ponto chave da sua política para o subcontinente, mas principalmente a satelitização dos prisioneiros geopolíticos (Bolívia e Paraguai). A finalidade principal era alcançar o Pacífico atraindo boa parte do cerne continental sul-americano e transformando-o na hinterlandia do porto de Santos.

A atuação brasileira em território boliviano foi ferrenha. O governo brasileiro construiu a ligação rodoviária conectando a Plataforma Central de Reserva brasileira a Corumbá no Mato Grosso do Sul, permitindo assim a ligação até Santa Cruz de La Sierra. Posteriormente o governo revolucionário boliviano construiu a autoestrada ligando Santa Cruz à Cochabamba, o que dava acesso do Porto de Santos até os portos chilenos do Pacifico. Em relação à conexão ferroviária, o governo brasileiro em 1957, terminou a obra da Ferrovia Noroeste ligando Bauru a Corumbá na divisa da Bolívia. Além disso, com os recursos previstos no Tratado de Petrópolis, os governos brasileiro e boliviano decidiram investir na construção da ferrovia ligando Corumbá a Santa Cruz de La Sierra. Naturalmente, por pressão argentina e pelas dificuldades de se romper os contrafortes andinos entre Cochabamba e Santa Cruz, construiu-se um ramal ligando Santa Cruz até Yacuíba (Departamento de Tarija) e daí até o norte argentino. Uma razão para a não concretização da ligação ferroviária Santos-Arica foi o temor das políticas imperialistas brasileiras por parte dos bolivianos (GLASSNER, 1988). Assim não foi por acaso que a malha ferroviária oriental boliviana se integra, ainda hoje, à ocidental apenas em território argentino.

Ainda em relação ao país andino, a empreitada pela sua satelitização por parte do Brasil foi mais adiante. De forma a impedir a implantação dos planos sociais durante o avanço da revolução de 1952, o governo brasileiro apoiou logística e militarmente o golpe militar cruceño de 1970, liderado pelo General Hugo Banzer. Poucos dias após a tomada do poder pelo militar, Brasil e Bolívia assinaram os "Convênios de Cochabamba", no qual o país andino se comprometia a fornecer ao "país-hermano" 240 milhões de pés cúbicos diários de gás natural, por um prazo de 20 anos, totalizando 1,7 trilhões de metros cúbicos. Em contrapartida, o Brasil se comprometia a construir o futuro gasoduto Brasil-Bolívia (GASBOL), uma usina petroquímica, uma usina siderúrgica para a jazida de Mutum $^{5}$, e a conexão ferroviária entre Santa Cruz e Cochabamba. Por último, concedia quatro zonas francas ${ }^{6}$ à Bolívia (MELLO, 1997, p. 158-159; SCHILLING, 1981).

Por outro lado, a geopolítica prática argentina procurava estabelecer seus interesses principalmente na área de hidrocarbonetos e de transportes. Sua estratégia principal era impedir a conexão Santos-Arica, ou na pior das hipóteses, criar alternativas melhores de forma a concorrer com este eixo. Além das conexões viárias que já vinham desde o passado colonial ligando os dois países, os argentinos empreenderam uma forte política ferroviária de forma a evitar o acesso brasileiro aos portos do Pacífico. Assim, além do ramal que ligava a capital argentina à capital boliviana, o país platino ainda construiu mais um ramal ligando o norte argentino até Santa Cruz de La Sierra de forma a diminuir a influência brasileira em um dos vértices do triângulo estratégico boliviano. Outras medidas importantes foram os acordos sobre a exportação de hidrocarbonetos na monta de 1,1 trilhões de metros cúbicos, sendo 150 milhões de pés cúbicos em 20 anos, além da construção do gasoduto YABOG integrando Rio Grande, na Bolívia, à rede de gasodutos em Salta, no norte argentino (MELLO, 1997, p. 158; MARES, 2006). Um segundo escopo da estratégia argentina era ter acesso ao minério de ferro de Mutún, porém os Acordos de Cochabamba, firmados entre Brasil 
e Bolívia, frustraram o intento argentino.

Ainda em 1980, o governo argentino apoiou massivamente a ditadura do general Garcia Mesa na Bolívia. A "questão boliviana" era vista pelo regime militar como um assunto central da sua política exterior, uma vez que se a Argentina quisesse ocupar uma posição de destaque na América do Sul deveria preencher os vácuos de poder no subcontinente. Prevendo uma redução relativa do poder americano na Bolívia, deviam então os argentinos aproveitar a oportunidade para fortalecer o seu poder de influência sobre o regime militar boliviano (RUSSEL, 1988). Em entrevista ao cientista político Roberto Russel, o general Videla afirmou categoricamente em 1980 que:

"Nós favorecemos a última opção porque nós não queríamos ter na América do Sul um governo que seria capaz de agir como Cuba o faz na América Central [...] Nós não estamos simplesmente ajudando os militares bolivianos, nós estamos ajudando o povo boliviano para que eles não se tornem algo no qual nós quase nos tornamos" (RUSSEL, 1988, p. 72, tradução nossa). ${ }^{7}$

Evidentemente, boa parte da infraestrutura física fixada para motivos de contenção e exploração dos recursos naturais bolivianos representaram posteriormente um novo desafio às iniciativas de integração, devido à desarticulação proposital dessas redes logísticas pelo confronto geopolítico entre Brasil e Argentina. Exemplos disso são a desarticulação da malha ferroviária boliviana e a escassez de infraestrutura viária comunicando a porção oriental boliviana à ocidental.

A partir do arrefecimento da contenção entre as semipotencias sul-americanas nos anos 1980, deu-se início uma série de iniciativas de integração visando superar esses obstáculos territoriais criados pela contenção em solo boliviano. Esse novo movimento de integração se deu principalmente na área de hidrocarbonetos, hidroviária e rodoviária. Um projeto importante visando a integração foi a construção da estrada Victor Paz Estenssoro, conectando Santa Cruz até Tarija e daí até Salta na Argentina. Posteriormente, a partir de um acordo entre o governo boliviano e brasileiro e a participação privada, construiu-se o gasoduto
Brasil-Bolívia (GASBOL), inconcluso desde os Acordos de Cochabamba. Na área hidroviária, o canal Tamengo foi construído, permitindo o acesso boliviano à hidrovia Paraguai-Paraná-Prata.

Outro projeto importante para o fortalecimento da integração foi a Iniciativa para a Integração da Infraestrutura Regional Sul-americana (IIRSA). Trata-se de um projeto visando a integração territorial sul-americana por meio de diferentes modais. Nesse novo planejamento, o território boliviano se torna um ponto central na interconexão de diferentes corredores, recebendo nada menos que 5 eixos de integração dos 9 já em execução. Nesse projeto tanto a infraestrutura de transporte, como também a de informação têm recebido substanciais aportes financeiros para a construção de infovias e transmissão de energia elétrica. Esses novos projetos vêm aproveitando a densidade territorial pré-existente, dessa forma, grande parte desses objetos técnicos são implantados em zonas densas de maior ocupação populacional e técnica, havendo, portanto, uma seletividade do território que se fundamenta principalmente nos arranjos territoriais anteriores.

Portanto, a confluência entre os discursos e as práticas geopolíticas de diferentes atores foi conformando uma área sobremaneira articulada no território boliviano ao longo de 60 anos de confrontação e integração. Nota-se na morfologia territorial a presença de um centro nevrálgico constituído justamente entre as cidades de Santa Cruz, Cochabamba e Tarija. Essa área densa com o formato triangular é constituída por eixos técnicos que integram a rede urbana de origem colonial, ainda vigente no altiplano (Oruro-Potosí-Tarija), e a rede urbana tributária do corredor econômico boliviano (La Paz-Cochabamba-Santa Cruz) à nova rede urbana que se origina das relações entre Santa Cruz e Tarija. Envoltos e bem articulados aos polos urbanos principais (Santa Cruz, Cochabamba, Tarija) há ainda centros secundários importantes como Potosí, Oruro, Sucre e Yacuiba - ver Mapa 1.

A partir de uma apreciação da morfologia, percebe-se então que as redes e corredores interligando os três centros principais possuem densidades técnicas diversas. Em relação ao eixo ligando Santa Cruz a Tarija, há a presença de ramais de gasoduto e oleoduto construídos nos anos 1990. Uma vantagem essencial a esse 
corredor é situar-se sobre as áreas onde se encontram os principais campos de gás e petróleo em território boliviano. Ademais, ainda durante os anos 50 foi construído um ramal rodoferroviário ligando Santa Cruz até Yacuíba. Nos últimos anos acrescenta-se ainda a implantação de uma rede de cabos de fibra ótica da empresa AES. Esse corredor se caracteriza principalmente pelas atividades de extração e refino de hidrocarbonetos e agropecuária extensiva.

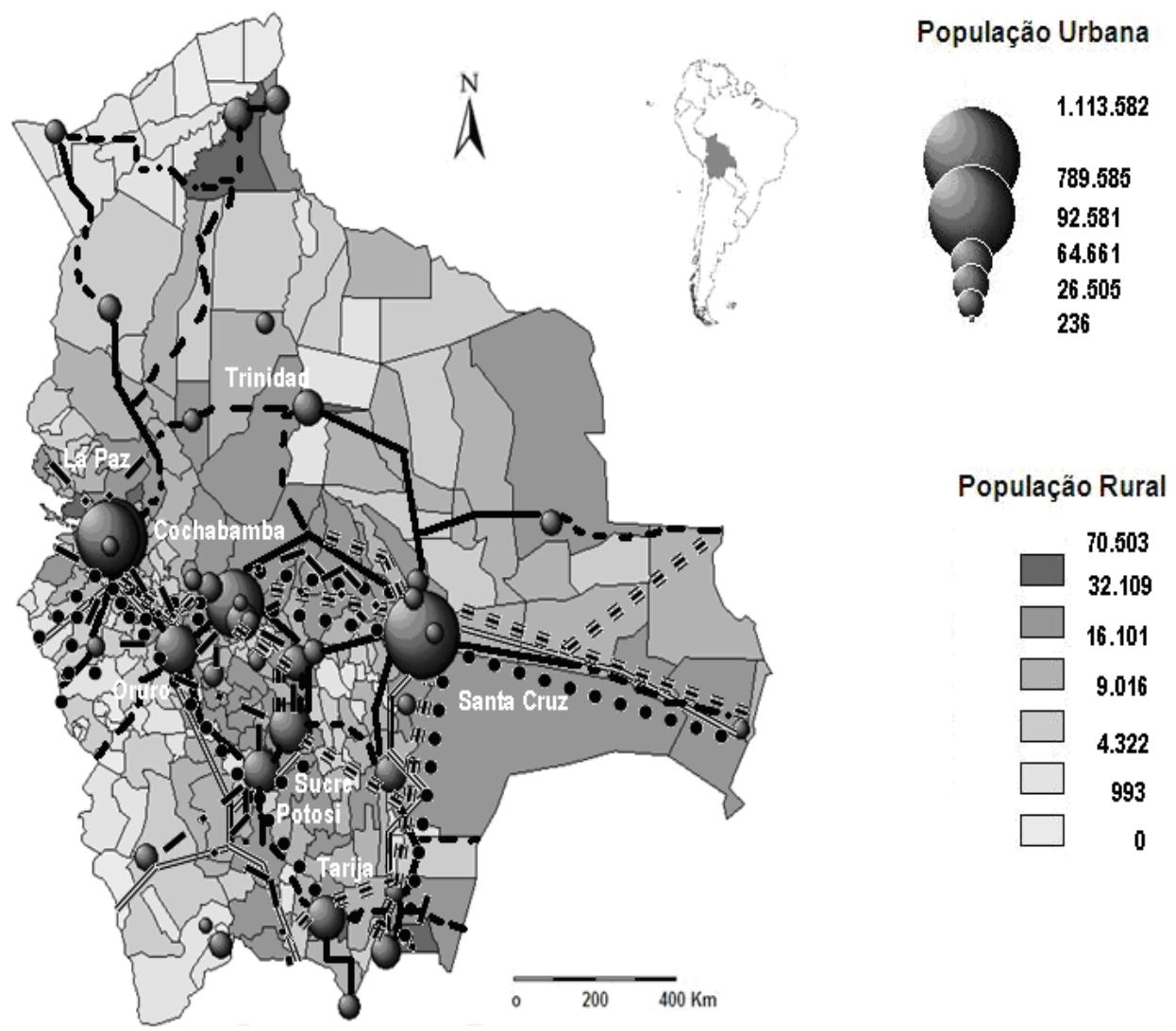

\section{Principais Redes Técnicas na Bolivia}

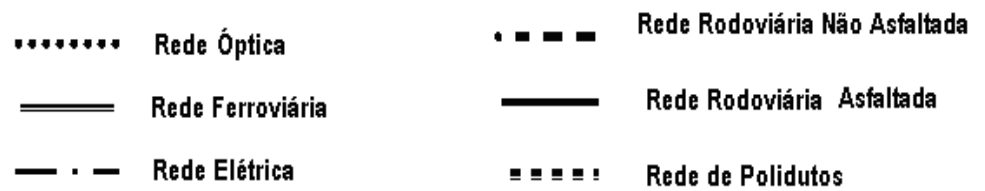

Realizado com Philcarto

Organizado por PFRIMER, Matheus (2010)

Mapa 1. Principais redes técnicas na Bolívia e a estruturação do Triângulo Estratégico Boliviano (Cochabamba-Santa Cruz-Tarija). Fonte - Organizado por Pfrimer (2010) com base em Pfrimer e Roseira (2009). 


\section{Heartland sul-americano? Do triângulo estratégico boliviano e outros discursos ao hub de integração sul-americano}

Ao verificarmos a densidade territorial boliviana e chegarmos à conclusão de que há uma morfologia triangular, devemos agora indagar qual a lógica dessa forma espacial. Estaríamos então caracterizando a existência do triângulo estratégico boliviano assim como os discursos geopolíticos o fizeram, ou, o caracterizaríamos como um construto fruto da interação entre discursos, práticas geopolíticas e estrutura territorial?

Embora a geopolítica formal tenha desempenhado um papel importante na estruturação do triângulo estratégico, por meio da participação direta de geopolitólogos em instituições dos regimes militares sul-americanos ${ }^{8}$, verificamos que os discursos, por si só, não foram responsáveis pela materialização desse arranjo triangular. Nota-se, por exemplo, que um dos fatores para o surgimento dessa nova estrutura territorial se deu a partir da descoberta de mais de $90 \%$ das reservas bolivianas de gás e petróleo em Tarija. Portanto, o próprio território e seus arranjos também incitaram intencionalidades nas práticas e discursos geopolíticos. Outro fator diz respeito à geopolítica prática implícita na perda de importância econômica e política da capital constitucional boliviana, Sucre, quando da transferência da sede administrativa para La Paz. Dessa forma, o translado de um dos vértices do triângulo estratégico de Sucre para Tarija, aponta na direção de que houve uma interação entre discursos, práticas e estrutura territorial.

Ao aceitarmos a concretude dessa morfologia territorial, não quer dizer que aceitemos categoricamente os postulados geopolíticos que cunharam o epíteto de Heartland Sul-americano para uma "suposta" estrutura territorial triangular na Bolívia, uma vez que o conceito de Mackinder ficava restrito ao seu próprio contexto geográfico e temporal (PFRIMER E ROSEIRA, 2009). Porém, não descartamos a importância geopolítica do território boliviano tanto para a finalidade de contenção, quanto para a de integração. Dessa forma, rejeitamos os discursos geopolíticos que caracterizaram a Bolívia como absurdo geográfico.

Ademais, quando aqui se fala de triângulo estratégico devemos ressaltar que não se trata mais de uma área estritamente de confrontação geopolítica. Embora inicialmente essa área tenha sido conformada por influência dos discursos geopolíticos colocados em prática durante o período de contenção, o novo período de integração a coloca como um grande centro articulador de fluxos, não apenas regionais, mas principalmente nacionais e que no contexto sul-americano passa a ter grande importância. Prova disso, são os diversos corredores de integração da IIRSA planejados para o território boliviano.

Finalmente cabe ressaltar que tanto os discursos como as políticas territoriais bolivianos atualmente procuram caracterizar o seu país como uma área de contato, voltada à finalidade de integração sul-americana. Substancial amostra disso foram os discursos do presidente Evo Morales e do Ministro das Relações Exteriores da Bolívia, Juan Ignácio Siles del Valle, caracterizando o país andino como área de contatos entre os países sulamericanos (MORALES, 2006; DEL VALLE, 2004). Acrescenta-se a isso o tratado de cooperação assinado entre os presidentes Lula, Michelle Bachelet e Evo Morales para a construção do corredor bioceânico Santos-Arica. Chega-se aqui ao consenso de que o território boliviano tem se estruturado atualmente em torno de um projeto de estado que o qualifica como um centro de coesão e dispersão de fluxos em escala continental, constituindo-se como um dos principais hubs de integração sulamericano.

\section{Notas}

1. Para o presente estudo práticas geopolíticas, são aquelas que envolvem a produção de um território por diferentes atores, com a finalidade de territorializar relações de poder através da estruturação de um arranjo territorial. Já os discursos geopolíticos se caracterizam por um conjunto de recursos retóricos com a finalidade de legitimar (a priori) ou justificar (a posteriori) essas práticas geopolíticas (DODDS, 2007).

2. Ao contrário da geopolítica prática, que é aquela oriunda das práticas de produção dos territórios, 
a geopolítica formal é aquela produzida a partir de discursos, conceitos e ideias construídas por intelectuais, grupos de estudos e pesquisadores (DODDS, 2007).

3. Nota-se com bastante frequência nos discursos geopolíticos do período de contenção a expressão integração no sentido dado pelo integralismo, ou seja, de que no contexto sul-americano os territórios dos países tampões (Uruguai, Bolívia e Paraguai) ficariam sob influência ("integrados") de interesses "maiores" que os seus próprios interesses. Normalmente, essa retórica se dava com a finalidade de legitimar os interesses dos países ABC (Argentina, Brasil e Chile).

4. Argentina, Brasil e Chile.

5. Trata-se de uma jazida de minério de ferro, estimada em 30 a 40 bilhões de toneladas que se encontra a $30 \mathrm{~km}$ da fronteira entre Brasil e Bolívia.

\section{Corumbá, Porto Velho, Belém e Santos.}

7. "We favored the latter option because we do not want to have in South America a government that would be able to act like Cuba does in Central America [...] We are not simply helping the Bolivian military, we are helping the Bolivian people so that they will not fall into something that we almost fell into."

8. O general Golbery do Couto e Silva foi ministro em três governos brasileiros. O General Augusto Pinochet foi presidente do Chile. A Agência Nacional de Desenvolvimento na Argentina foi dirigida pelo General Juan Enrique Guglialmelli.

\section{Bibliografia}

AGNEW, John; CORBRIDGE, Stuart. Mastering space: hegemony, territory and international political economy. London: Routledge, 1995, p. 260.

ANDRADE, Everaldo de Oliveira. A revolução boliviana. São Paulo: UNESP, 2007, p. 182.

BADIA MALAGRIDA, Carlos. El factor geográfico en la política sudamericana. 1 ed., Madrid: Jaime Ratés, 1919, p. 384.

BAPTISTA GUMUCIO, Mariano. La viabilidad de Bolivia. In: BAPTISTA GUMUCIO, Mariano ; SAAVEDRA WEISE, Agustin. Antologia Geopolitica de Bolivia. Cochabamba: Los Amigos del Libro, 1978 , p. $119-151$.

BECKER, Bertha Koiffmann. A geografia e o resgate da geopolítica. Revista Brasileira de Geografia, Rio de Janeiro, v. 50, n. especial, 1988, p. 99-125.

BECKER, Bertha Koiffmann. O uso político do território: questões a partir de uma visão do terceiro mundo. In: BECKER, Bertha; COSTA, Rogério H. da; SILVEIRA, Carmen B. (Org.). Abordagens políticas da espacialidade. Rio de Janeiro: UFRJ, 1983. p. 1-8.

BOSCOVICH, Nicolas. Geostratégia de La Cuenca Del Plata. Buenos Aires: El Cid, 1979, p. 235.

BOWMAN, Isaiah. The New World. Problems in Political Geography. 4 ed., New York and Chicago: World Book Company, 1928, p. 803.

CAÑAS MONTALVA, Ramon. Fronteras: la política internacional de Chile frente a los imperativos geopolíticos desprendidos de su transcendente posición en el Pacífico Sur antártico. Revista Geográfica de Chile Terra Australis, n. 17, 1959, p. 15-36.

CARLÉS, Fernando J. Algunos aspectos de la geopolítica boliviana. Buenos Aires: Instituto de Derecho Internacional, 1950, p. 89.

CENTRO DE DOCUMENTACIÓN E INFORMACIÓN BOLIVIA (CEDIB). La gestión de los recursos naturales no renovables de Bolivia. Cochabamba: CEDIB, v. 2, 2005, p. 101.

COSTA, Wanderley Messias da. Políticas Territoriais Brasileiras no Contexto da Integração Sul- 
Americana. Rio de Janeiro, Revista Território, n. 07, Jul./Dez. 1999, p. $25-41$.

COSTA, Wanderley Messias da. Brasil e a América do Sul: cenários geopolíticos e os desafios da integração. Confins, v. 7, 2009, p. 1-27.

COUTO E SILVA, Golbery do. Geopolítica do Brasil. Rio de Janeiro: Livraria José Olympio, 1955, p. 266.

DEL VALLE, Juan Ignácio Siles. A nova política externa da Bolívia. Revista Diplomacia, Estratégia e Política, n. 1, 2004, p. 22-40.

DODDS, Klaus. Geopolitics and Geographical imagination of Argentina. In : DODDS, Klaus ; ATKINS, John. Geopolitical Traditions: a century of geopolitical thought. London and New York: Routledge, 2000, p. 150-184.

DODDS, Klaus-John. Geopolitics, cartography and the state in South America. Political Geography, v. 12 , n. 4, July, 1993, p. 361-381.

DODDS, Klaus. Geopolitics. A very short introduction. New York and Oxford: Oxford University Press, 2007, p. 182.

DODDS, Klaus. Political Geography III: critical geopolitics after ten years. Progress in Human Geography, v. 25, n. 3, 2001, p. 469-484.

DUNKERLEY, James. Rebellion in the veins: political struggle in Bolivia 1952-1982. London: Verso, 1984, p. 385.

EGLER, Claudio A. G. Mercosul: um território em construção? Ciência e Cultura (SBPC), v. 58, n. 1,2006 , p. 24-28.

GLASNER, Martin Ira. Bolivia's Orientation: Toward the Atlantic or the Pacific? In: KELLY, Philip; CHILD, Jack. Geopolitics of the Southern cone and Antarctica. Boulder and London: Lynne Rienner Publishers, 1988, p. 154-169.

GUGLIALMELLI, Juan Enrique. Argentina-Brasil, enfrentamiento o alianza para la liberación. Estratégia, no. 36, 1975, p. 1-29.

HEPPLE, Leslie. The revival of geopolitics. Political Geography quarterly. v. 5, n. 4, 1986a, p. s21-s36.

HEPPLE, Leslie. Geopolitics, generals and the state in Brazil. Political Geography Quarterly. v. 5, n. 4, October, 1986b, p. 279-290.

HEPPLE, Leslie. South American Heartland: the Charcas, Latin American geopolitics and global strategies. Political Geography, v. 170, n. 4, December, 2004, p. 359-367.

INE. INSTITUTO NACIONAL DE ESTADÍSTICA. Censo sociodemografico por ciudades capitales. La Paz, 2001, p. 920.

INE. INSTITUTO NACIONAL DE ESTADÍSTICA. Cochabamba: resultados departamentales. La Paz, 2002. (Serie II, Resultados departamentales, 3), p. 300 .

INICIATIVA PARA A INTEGRAÇÃO DA INFRAESTRUTURA REGIONAL SUL-AMERICANA (IIRSA). Cartera IIRSA: Ejes de integración y desarrollo.2008. Disponível em: <http://www. iirsa.org/Cartera. asp?CodIdioma $=$ ESP. $>$ Acessado em: 10 Ago. 2008

KELLY, Philip. Checkerboards and Shatterbelts: the geopolitics of South America. Austin: Texas University Press, 1997, p. 239.

KELLY, Philip. Traditional Themes of Brazilian Geopolitics. In: KELLY, Philip; CHILD, Jack. Geopolitics of the Southern cone and Antarctica. Boulder and London: Lynne Rienner Publishers, 1988, p. 111-122.

KELLY, Philip. A critique of critical geopolitics. Geopolitics, v. 11, n. 1, march, 2006, p. 24-53.

LAVAUD, Jean Pierre. Bolivie: la nation incertaine. Hérodote, Paris, n. 99, 2000, p. 161-181.

MARES, David R. Natural gas pipelines in the 
Southern Cone. In: VICTOR, David G.; JAFFE, Amy M.; HAYES, Mark H. Natural Gas and Geopolitics. Cambridge: Cambridge University Press, 2006, p. 169-201.

MARINI, José Felipe. Desarrollo y seguridad de la Argentina en el marco geopolítico internacional. Buenos Aires: Librería Hachette, 1980 , p. 237.

MARTIN, Andre Roberto. Brasil, Geopolítica e Poder Mundial: o Anti-Golbery. Tese (Livredocência), Universidade de São Paulo, São Paulo, 2007, p. 118.

MACKINDER, Halford. The Geographical Pivot of History. Geographical Journal, n. 23, 1904, p. 421-437.

MELLO, Leonel Itaussu de Almeida. Geopolítica do Brasil e a Bacia do Prata. Manaus: Editora da Universidade Federal do Amazonas, 1997, p. 300.

MENDOZA, Jaime. El macizo boliviano. La Paz: Imp. Arnó Hnos, 1935, p. 277.

MENEZES CIUFARDI, Emilio. Maintaining a regional navy with very limited resources: the Chilean case, 1900-1990. Defense Analysis, n. 7, 1991, p. 345-362.

MORALES, Evo. Bolívia, fator de integração. Revista Diplomacia, Estrategia e Política, n. 4, 2006, p. 16-27.

Ó'TUATHAIL, Geroid. Critical Geopolitics. The Politics of Writing Global Space. London: Routledge, 1996 , p. 230.

PAREJA, Rolando Aguilera. Modelo Macroespacial del Desarrollo Boliviano. In: BAPTISTA GUMUCIO, Mariano; SAAVEDRA WEISE, Agustin. Antologia Geopolitica de Bolivia. Cochabamba : Los Amigos del Libro, 1978, p. 189-222.

PEREIRA, Osny Duarte. Itaipu: prós e contras. Rio de Janeiro: Paz e Terra, 1984, p. 367.
PFRIMER, Matheus; ROSEIRA, Antonio Marcos. Transformações territoriais na Bolívia: um novo triângulo estratégico? In: ENCONTRO LATINO AMERICANO DE GEÓGRAFOS, 12., 2009, Montevideo. Anais... Montevideo: Universidad de Montevideo, 2009. p. 1-15.

PINOCHET, Augusto Ugarte. Geopolítica. Santiago: Andrés Belo, 1977, p. 248.

PITTMANN, Howard T. From O'Higgins to Pinochet: applied Geopolitics in Chile. In: KELLY, Philip; CHILD, Jack. Geopolitics of the Southern cone and Antarctica. Boulder and London: Lynne Rienner Publishers, 1988, p. 173-183.

QUAGLIOTTI DE BELLIS, Bernardo. The La Plata Basin in the Geopolitics of the Southern Cone. In: KELLY, Philip; CHILD, Jack. Geopolitics of the Southern cone and Antarctica. Boulder and London: Lynne Rienner Publishers, 1988, p. 125-143.

QUAGLIOTTI DE BELLIS, Bernardo. EI acondicionamiento territorial para la integración regional. Geosur, n. 117-118, 1990, p. 2- 47.

QUIROGA, Eduardo Arze. "El factor geográfico en la política sudamericana" de Carlos Badia Malagrida. In: BAPTISTA GUMUCIO, Mariano; SAAVEDRA WEISE, Agustin. Antologia Geopolítica de Bolivia. 1 ed., Cochabamba e La Paz: Los Amigos del Libro, 1978, p. 81-105.

RODRIGUES, Lysias. Geopolítica do Brasil. Rio de Janeiro: Biblioteca Militar, 1947, p. 140.

RUSSEL, Roberto. Argentina: Ten Years of Foreign Policy. In: KELLY, Philip; CHILD, Jack. Geopolitics of the Southern cone and Antarctica. Boulder and London: Lynne Rienner Publishers, 1988, p. 67-82.

SCHILLING, Paulo. O expansionismo brasileiro: a Geopolítica do General Golbery e a diplomacia do Itamaraty. São Paulo: Global, 1981, p. 288.

TAMBS, Lewis (1965) Fatores em America Latina 
in: GUMUCIO, Mariano Baptista e WEISE, Agustín Saavedra. Antologia Geopolitica en Bolívia. Cochabamba: Ed. Los Amigos del Libro, 1978, p. 229-244.

TAYLOR, Peter J., FLINT, Colin. Political geography: world-economy, nation-state and locality. 4 ed. London: Prentice Hall, 2000, p. 412.

TRAVASSOS, Mário. Projeção Continental do Brasil. São Paulo: Companhia Editora Nacional, 1935, p. 206.

VALENCIA VEGA, Alípio. Geopolítica en Bolívia. La Paz: Juventud, 1968, p. 380.

VALENCIA VEGA, Alípio. Geopolítica del Litoral Boliviano. La Paz: Urquiza, 1982, p. 568.

VELILLA DE ARELLAGA, Julia. Paraguai: um destino geopolítico. Asunción: Instituto Paraguayo de Estudios Geopolíticos y Relaciones Internacionales, 1982 , p. 281.

VELILLA DE ARELLAGA, Julia. An Energy and Iron
Community in the La Plata Basin. In: KELLY, Philip; CHILD, Jack. Geopolitics of the Southern cone and Antarctica. Boulder and London: Lynne Rienner Publishers, 1988, p. 144-153.

VIDELA, Jorge Rafael. Discurso. Clarín, Buenos Aires, 6 de Agosto de 1980, p. 2-3 apud RUSSEL, Roberto. Argentina: Ten Years of Foreign Policy. In: KELLY, Philip; CHILD, Jack. Geopolitics of the Southern cone and Antarctica. Boulder and London: Lynne Rienner Publishers, 1988, p. 67-82.

WHITTLESEY, Derwent. The earth and the state: a study of political geography New York: Henry Holt Company, 1944, p. 618.

ZANATTA, Lóris. The rise and fall of the third position. Bolivia, Perón and the Cold War, 19431954. Desarrollo Economico, v.45, no. 177, 2006, p. 1-27.

ZAVALETA MERCADO, Rene. El desarrollo de la conciencia nacional. Montevideo: Dialogo, 1967, p. 181. 